a kind of scientific jackdaw. So I invite you to regard experience, in the fullest sense of that word, as formed in a complex of patterns largely made by the experiencer, patterns in some cases interlacing, in others forming a hierarchy of increasing generality. Or, to start from the other end, let us take our science to be the study of all the detailed embroideries upon that most common and most comprehensive of patterns, the formula of which runs: $\mathrm{He}$ was born, and strove to master his world for his own safety; he mated, fought for his offspring, and died.

\title{
Campbell Swinton and Television
}

\author{
By Dr. J. D. McGee
}

$\mathrm{T}$ HE successful inauguration by the British Broadcasting Corporation of the high-definition television transmitting station at Alexandra Palace has focusea the attention of the technical world on the successful development of the allelectric, instantaneous system of transmission. The degree of success achieved shows that the cathode ray transmitting tube has at last emerged from the research laboratory to take its place as the complement of the receiving cathode ray tube. The latter is well known, and has been recognized for some years as the most effective means for picture reception, and is now a highly developed commercial product. Modern television technique, which will withstand the criterion of the flickerless talking picture, both from the producing and reception points of view, has only been made possible by the development of the receiving and transmitting cathode ray tubes. This development is the result of improvement in technique brought about by the work of many scientific investigators in research laboratories throughout the world.

The manufacture of the modern cathode ray tube for picture reception has evolved slowly as improvements in vacuum technique, glass manufacture, fluorescent materials have been made, while the transmitting tube inherits also the wealth of developments in photo-electric technique. Besides these key units, the whole television equipment-amplifiers, scanning oscillators, pulse generators, cables, radio transmitters, etc.-have each been improved to a stage where they are capable of dealing with the enormous frequency bands, exacting phase conditions, etc., which are necessary for the production of high-definition flickerless picture. This has been achieved by improvement in valve and circuit technique spread over the last twenty years.

The object of this article is to pay a tribute to the memory of a man who probably thought more deeply, clearly and disinterestedly about television than any other of his time and who, had he but lived six years longer, would, I believe, have agreed that his life-long dream had at last come true.

The late Mr. A. A. Campbell Swinton was the first to propose ${ }^{1}$ an all-electric system of television in 1908, and continued to urge its claims ${ }^{2}$ up until the time of his death in 1930. Sir Richard Gregory has recently reminded us of Campbell Swinton's early suggestions in connexion with television", but it might not be redundant to show how Campbell Swinton continued to develop his ideas as technical methods advanced during the remaining twenty years of his life. He first suggested the idea in a short letter to NATURE in $1908^{1}$, later explaining and amplifying it in his presidential address to the Rontgen Society on November 7, 19114. This plan of twenty-eight years ago only required the application of modern technique to become the non-mechanical system now installed at Alexandra Palace, and still in course of development in Germany and America.

It is worth while quoting at some length from the published papers of Campbell Swinton in order to emphasize not only the remarkable accuracy with which he visualized his scheme, but also the kindly unassuming manner in which he presented it to the world.

Campbell Swinton's definition of television is worth noting when considering modern developments, in order to appreciate the difference between television proper and telekinematography. $\mathrm{He}$ defines television thus $s^{5}$ : "If you point a photo. graphic camera at any view or object, whatever is in front of the lens is depicted on the ground glass screen, and what I mean by television is some method whereby what is depicted on such a screen, with any motions or other changes that may be taking place, is electrically transmitted to a distance and made reappear instantaneously on a similar screen at the distant station." This conception of television is implicit in all his early publications.

Referring to a letter from Mr. Shelford Bidwell in Nature of June $4,1908^{6}$, in which the difficulty 
of obtaining synchronism with mechanical television systems was discussed, Campbell Swinton observed $^{\mathbf{1}}$ :

". . . this part of the problem of obtaining distant electric vision can probably be solved by the employ. ment of two beams of kathode rays (one at the transmitting and one at the receiving station) synchronously deflected by the varying fields of two electromagnets placed at right angles to one another and energised by two alternating electric currents of widely different frequencies, so that the moving extremities of the two beams are caused to sweep synchronously over the whole of the required surfaces within the one-tenth of a second necessary to take advantage of visual persistence.

"Indeed, so far as the receiving apparatus is concerned, the moving kathode beam has only to be arranged to impinge on a sufficiently sensitive fluorescent screen, and given suitable variations in its intensity, to obtain the desired result.

"The real difficulties lie in devising an efficient transmitter which, under the influence of light and shade, shall sufficiently vary the transmitted electric current so as to produce the necessary alterations in the intensity of the kathode beam of the receiver, and further in making this transmitter sufficiently rapid in its action to respond to the 160,000 variations per second that are necessary as a minimum.

"Possibly, no photoelectric phenomenon at present known will provide what is required in this respect, but should something suitable be discovered, distant electric vision will, I think, come within the region of possibility."

This 1908 statement is, undoubtedly, the first published suggestion of a television system which has now been developed on a commercial basis to produce pictures of even higher order of definition than the inventor then proposed as a satisfactory minimum. In the elaborated account of this suggestion in his lecture to the Röntgen Society in 1911, Campbell Swinton gives more details of his proposed transmitting tube, and while it is crude in comparison with a modern transmitting tube, anyone who is familiar with the development of the subject will agree that it was an enormous step in the right direction. It is characteristic of the man that, in proposing his suggestion, he emphasized that" :

\footnotetext{
"it is an idea only, and the apparatus has never been constructed. Furthermore, I would explain that I do not for a moment suppose it could be got to work without a great deal of experiment and probably much modification. It is, indeed, only an effort of my imagination, and can be useful merely as a sug. gestion of a direction in which experiment might possibly secure what is wanted. What, however, is claimed is that, so far as I am aware, it is the first suggested solution of the problem of distant electric vision in which the difficulty of securing the required extreme rapidity and accuracy of motion of the parts is got over by employing for these parts things of the extreme tenuity and weightlessness of cathode rays".
}

What must astonish the modern television engineer is the accuracy of Campbell Swinton's idea, when he reflects that, at the time it was suggested, radio communication was in its infancy, radio valves practically unknown, vacuum technique very primitive, photo-electric cells very inefficient.

In the period following the Great War, much time and money was spent in developing mechanical systems of television to the present high limits of mechanical efficiency, but the all-electric system has proved, after a comparatively short period of development work, to be much more powerful.

Campbell Swinton repeatedly pointed out the limitations of the mechanical methods, and repeatedly urged that the development of the all-electric system should be taken up seriously by some large industrial research laboratory. "There are, at any rate," he wrote", "no theoretical objections to the scheme, and it is now for some ingenious experimenter to work out the details of the apparatus and to give the world some form of television by this means."

It may justly be asked-_"Why did not Campbell Swinton develop his own scheme?" The answer is twofold-first, that he did carry out experiments along lines which have recently proved successful, and second, that physical technique was at that time quite inadequate to deal with the problem. In a letter to Nature of October 23, 1926', Campbell Swinton wrote:

\footnotetext{
"I actually tried some not very successful experiments in the matter of getting an electrical effect from the combined action of light and cathode rays incident upon a selenium-coated surface. . . . The transmitting apparatus consisted of a home-made Braun oscillograph in which a metal plate coated with selenium was substituted for the usual fluorescent screen, the image to be transmitted being thrown by a lens upon the selenium surface, and the end of the cathode ray beam being caused electromagnetically to traverse the projected image. Experiments were also tried in receiving with a Braun tube which I purchased in Germany, but in its then 'hard' form it proved very intractable."
}

It is interesting to note that this actual experiment has been repeated recently in the Research Laboratories of Electric and Musical Industries Ltd., under the direction of the present writer, and has proved successful. Two important features of the modern transmitting tube are described in this short note, namely, the use of a 'signal plate' and the projection of the optical image on to the same surface as is scanned by the electron beam-another step in the right direction.

This solution of the problem of high-definition television was not a 'one-man-job', as Campbell 
Swinton saw clearly', but one which could only be solved by the close co-operation of a large band of research workers having at their disposal the facilities of a well-equipped research laboratory. The problem has been attacked during the last decade in many of the large industrial research laboratories in America, Germany and Great Britain, and the progress in many of these organizations has been roughly parallel, but it is fitting that Great Britain should be the first to inaugurate a public television service employing the system which was first outlined twenty-eight years ago by a distinguished British scientist.

\footnotetext{
1 NATURE, 78, 151 (June 18, 1908).

"Autobiographical and other Writings". A. A. Campbell Swinton, pp. 131-137. (Longmans, Green and Co., Ltd.)

3 NATURE, 13\%, 984 (June 13, 1936).

- J. Rontgen Soc, Jan. 1912, p. 7

- NATURE, 78, 105 (June 4, 1908)

" "Autoblographical and other Writings". A. A. Campbell Swinton, p. 137 .

WiTURE, 118, 590 (Oct. 23, 1926).

- Wireless World, 14, 118 (1924).
}

\section{Stratosphere Flight}

$\mathrm{T}^{\mathrm{n}}$ HE recent world's height record, for aeroplanes, of $49,967 \mathrm{ft}$., set up by Squadron. Leader F. R. D. Swain, R.A.F., piloting a Bristol monoplane fitted with a special type Bristol Pegasus engine, has served to focus a certain attention upon the question of flights at great altitudes, and the possible advantages to be derived therefrom.

The most obvious gain comes from the reduction of the resistance to the aircraft's motion as the density of the air to be displaced decreases, which, if other conditions remained the same, would result in increases of speed of a valuable order. For example, in round figures, an aeroplane of maximum speed 180 miles per hour at sea-level would travel at 550 miles per hour at a height of a little more than ten miles. This is equivalent to London to New York (3,000 miles) in $5 \frac{1}{2}$ hours, neglecting the time taken to climb to and descend from that altitude.

Other probable advantages are a relative wind in a direction opposite to the rotation of the earth, if a shear effect in the belt of atmosphere rotating with the earth may be assumed; the absence of meteorological and electrical disturbances with their effect upon accurate navigation, that would also allow routes to follow the shortest line from point to point irrespective of the conditions upon the earth's surface, as for example across the polar regions; and the psychological effect of constant sunshine, lack of clouds and equable temperature conditions are possibly not to be ignored.

The principles upon which the flight of the present-day heavier-than-air machine are based, however, make use of the density of the atmosphere in several ways in which its rarefaction at great heights would be a definite disadvantage, and may possibly set a limit upon entering the stratosphere which will make it not worth while, at least as a commercial transport proposition. The importance of doing so for the purpose of research into the physical conditions comes within a different category.

The power plant gives the machine a forward motion through the medium of an airscrew, this being required in order that the circulation of air around the lifting surfaces may be set up, resulting in the necessary lift and control. A reduction in air density will lessen this thrust and thus reduce the lift indirectly by reducing the speed, in addition to the direct loss of lift. Further, use of full power would result in excessive rotational speed of the airscrew due to the thinness of the air. Variable pitch propellers, already a practicable proposition to a limited extent, will help in this respect.

The internal combustion engine, the present-day power plant, requires a definite weight of oxygen for the proper combustion of its fuel. The rarefied and poor quality air can be forced into the engine, up to a certain limit, by super-chargers, and after this it does not appear to be impossible to carry a supply of oxygen under pressure to make up this deficiency, more especially as a supply will probably have to be carried for the occupants of the aeroplane. The physiological requirements of the passengers and crew will call for extra size and weight of the cabin, which will have to be of sufficient capacity for the required change of air, to carry apparatus for storing the oxygen and for absorption of the carbon dioxide and moisture exhaled, and will almost certainly have to be heat insulated. This may be against the low temperature of the surrounding atmosphere, or against heat generated by the friction set up by the rubbing of the air at these high speeds. Which will predominate, and how far one will balance the other, will depend upon the heights and speeds attained.

This state of affairs is already partly achieved, and its consummation does not appear to be beyond the bounds of possibility, at least, as a scientific experiment. As an everyday transport 